\title{
Brain Blood Flow and Ventilatory Response to Hypoxia in Sedated Newborn Piglets
}

\author{
CLEIDE SUGUIHARA, EDUARDO BANCALARI, AND DOROTHY HEHRE \\ University of Miami School of Medicine, Department of Pediatrics, Division of Neonatology, \\ Miami, Florida 33101
}

\begin{abstract}
To evaluate the relationship between brain blood flow and ventilatory response to hypoxia, seventeen sedated, spontaneously breathing newborn piglets were studied. Minute ventilation $\left(\dot{\mathrm{V}}_{\mathrm{E}}\right)$ was measured by pneumotachograph, cardiac output by thermodilution and total brain and brain stem blood flows with radiolabeled microspheres. Measurements were performed while the animals were breathing room air and after $10 \mathrm{~min}$ of hypoxia induced by breathing $\mathbf{1 0} \% \mathrm{O}_{2}$. Two patterns of ventilatory response to hypoxia were observed in the study animals. All animals increased $\dot{V}_{E}$ during the 1st min of hypoxia, but nine (mean $\pm S D$; age $5 \pm 1.3 \mathrm{~d}$; wt $1828 \pm 437 \mathrm{~g}$ ) sustained increased $\dot{V}_{E}$ after $10 \mathrm{~min}$ of hypoxia $\left(\uparrow \dot{V}_{E}\right.$ group). The remaining eight animals (age $5 \pm 1.2 \mathrm{~d}$; wt $1751 \pm 168 \mathrm{~g}$ ) had decreased $\dot{V}_{E}$ at $10 \mathrm{~min}$ of hypoxia to values less than their room air baseline $\left(\downarrow \dot{V}_{E}\right.$ group). The decrease in $\mathrm{PaO}_{2}$ during hypoxia was similar in both groups, however the $\mathrm{PaCO}_{2}$ decreased significantly only in the $\uparrow \dot{V}_{E}$ group. Although cardiac output increased significantly during hypoxia in both groups, the values during normoxia and hypoxia were lower in the $\downarrow \dot{V}_{\mathrm{E}}$ group ( $p<$ $0.001)$. Arterial blood pressure increased significantly during hypoxia only in the $\uparrow \dot{V}_{E}$ group. The increase in total brain and brain stem blood flows with hypoxia was similar in both groups, despite the two different patterns of ventilatory response to hypoxia. These data suggest that in this animal model the distinct patterns of ventilatory response to hypoxia are not related to the changes in total brain or brain stem blood flows that occur during hypoxia. (Pediatr Res 27: 327-331, 1990)
\end{abstract}

\section{Abbreviations}

$\dot{\mathbf{V}}_{\mathrm{E}}$, minute ventilation

$\mathrm{CO}$, cardiac output

$\mathrm{BBF}$, total brain blood flow

BSBF, brain stem blood flow

RA, room air

ABP, arterial blood pressure

$V_{t}$, tidal volume

Cdyn, dynamic lung compliance

$\mathbf{R}_{\mathrm{L}}$, pulmonary resistance

The ventilatory response to hypoxia during the first days after birth is characterized in humans and several animal species by a transient initial increase in ventilation (1-2 $\mathrm{min})$, followed by a

Received June 22, 1989; accepted December 12, 1989.

Correspondence: Cleide Suguihara, M.D., University of Miami School of Medicine, Department of Pediatrics (R-131), P.O. Box 016960, Miami, FL 33101.

Supported in part by the State of Florida, Department of Health and Rehabilitative Services, Children's Medical Services, and the University of Miami: Project Newborn. marked decline in $\dot{\mathrm{V}}_{\mathrm{E}}$ to values slightly above or below prehypoxia basal values $(1-6)$. The mechanism responsible for this biphasic response to hypoxia has not been completely elucidated. Various neurotransmitters or modulators released during hypoxia such as endorphins, $\gamma$-aminobutyric acid, prostaglandins, and adenosine have been suggested as possible mediators of the late decrease in ventilation $(2,7-10)$. Other possible explanations have included changes in lung mechanics, a decrease in the metabolic rate, respiratory muscle fatigue, and inhibition of peripheral chemoreceptors $(3,11-14)$. The increase in cerebral blood flow that occurs in response to hypoxia can induce a decrease in $\mathrm{PCO}_{2}$ and $\mathrm{H}^{+}$in the CNS extracellular fluid and this may also account for the decrease in respiratory drive (15). Conversely, the absence of a normal cardiovascular response and the increase in cerebral blood flow that normally occurs during hypoxemia can aggravate CNS hypoxia and lead to CNS depression (16).

We hypothesized that the observed differences in the ventilatory response to hypoxia in newborn piglets may be related to differences in their cardiovascular and brain blood flow response to hypoxia.

Our purpose was to define the relationship between the ventilatory response to hypoxia and the changes in cerebral blood flow in newborn piglets.

\section{MATERIALS AND METHODS}

Seventeen piglets $\leq 7 \mathrm{~d}$ of age were anesthetized with ketamine (20 mg/kg intramuscularly) and xylazine $(2 \mathrm{mg} / \mathrm{kg}$ intramuscularly) for surgical procedures. Lidocaine hydrochloride $(0.5 \%)$ was used for local anesthesia. The animals were then sedated with chloral hydrate $(200 \mathrm{mg} / \mathrm{kg}$ p.o. every $3 \mathrm{~h})$ throughout the study period. Experimental trials were performed at least $2 \mathrm{~h}$ after administration of ketamine. The left femoral and right brachial arteries and femoral vein were cannulated and used for systemic ABP measurement, blood sampling, and infusion of fluids. The right femoral artery was cannulated with a $3.5 \mathrm{~F}$ Argyle catheter (Sherwood Medical, St. Louis, MO), which was advanced into the left ventricle and used for radiolabeled microspheres injection. The left external jugular vein was cannulated and the catheter advanced into the right atrium for injection of cold saline for measurement of CO. A 5 F Swan Ganz catheter was introduced into the right external jugular vein and advanced under fluoroscopy into the left pulmonary artery. CO was measured by thermodilution using a cardiac output computer (95510A, Edwards Laboratory, Santa Ana, CA). Vascular pressures were measured with pressure transducers (model P23-ID; Gould Instruments, Cleveland, $\mathrm{OH}$ ) and recorded on a multichannel recorder (model 260, Gould Instruments).

A tracheostomy was performed and a $3.5-\mathrm{mm}$ endotracheal tube inserted while the animals were anesthetized with ketamine and xylazine. The animals did not exhibit signs of pain or discomfort during the study periods under chloral hydrate sedation. The rectal temperature was continuously monitored with a 
thermistor probe and skin temperature was maintained at $38.5^{\circ} \mathrm{C}$ by means of a servo-controlled radiant warmer. The animals received an infusion of $6 \mathrm{~mL} /(\mathrm{kg} \cdot \mathrm{h})$ of $5 \%$ dextrose solution through a peripheral vein and a $2.5 \mathrm{~mL} / \mathrm{h}$ of heparinized saline solution $(10 \mathrm{U} / \mathrm{mL})$ through the pulmonary artery catheter.

Handling and care of animals was in accord with the guidelines of the National Institutes of Health and this study protocol was approved by the Animal Care Committee of the University of Miami.

Pulmonary mechanics. Pulmonary mechanics were measured to investigate the possible influence of changes in mechanical factors on the ventilatory response to hypoxia. Respiratory flow was measured by a heated Fleish no. 00 pneumotachograph (OEM Medical, Richmond, VA), a differential pressure transducer (model MP45, Validyne Engineering Co., Northridge, CA) and a pressure amplifier (Gould Instruments). The flow signal was electronically integrated to obtain $V_{t}$ using a Gould integrator amplifier. Calibration of $V_{t}$ was done before and after each study using a calibrated glass syringe. $\dot{V}_{E}$ was obtained by the sum of inspiratory volumes measured over 1-min periods of regular respiration. Esophageal pressure was measured by a water filled $8 \mathrm{~F}$ feeding tube placed in the lower third of the esophagus and attached to a pressure transducer (model P23-ID, Gould Instruments) and a Gould pressure amplifier calibrated with a water manometer. Proximal airway pressure was measured by an air filled large-bore catheter attached to a side tap in the endotracheal tube adaptor and to a pressure transducer (model P23-ID, Gould Instruments). Airflow, $V_{t}$, and airway and esophageal pressures were recorded on a multichannel recorder (model 260; Gould Instruments). Cdyn and $R_{L}$ were calculated from this trace (17).

Cerebral blood flow measurements. Regional cerebral blood flow was measured with the tracer microspheres technique (18). Microspheres $(15.0 \pm 1.0 \mu \mathrm{m})$ labeled with ${ }^{141} \mathrm{Ce},{ }^{85} \mathrm{Sr},{ }^{46} \mathrm{Sc}(3 \mathrm{M}$, St. Paul, MN) and ${ }^{113} \mathrm{Sn}$ (NEN, Boston, MA) were used in random order in each animal. Approximately 0.7-1.2 million microspheres were injected into the left ventricle over a period of 20-30 s. For $10 \mathrm{~s}$ before, during, and $60 \mathrm{~s}$ after the injection of microspheres, reference arterial blood samples were withdrawn from the right brachial artery at rate of $0.97 \mathrm{~mL} / \mathrm{min}$ (19). At the end of the experiment the animal was killed and the brain was divided into cerebrum, cerebral gray and white matter, caudate nucleus, hippocampus, thalamus-hypothalamus, midbrain, cerebellum, pons, and medulla. These tissues were placed into counting vials that were weighed without and with tissues. Radioactivity from the tissue and reference blood samples was counted for 5 min by a two-channel $\gamma$-counter (model 1191, TM Analytic, Elk Grove Village, IL). Blood flow was calculated with the formula $\dot{Q}=A_{t} \cdot \dot{Q} r / A_{r}$, where $A_{t}$ and $A_{r}$ are the activity $(\mathrm{cpm})$ in the tissue and reference blood and $\mathrm{Q} r$ is the rate of withdrawal of the blood sample. Blood flow to each region was expressed by $100 \mathrm{~g}$ of tissue. The BSBF included the medulla, pons, and midbrain blood flows. The accuracy of the radiolabeled microspheres technique requires that the number of microspheres in each tissue be more than 385 (18). The mean values \pm SEM for the number of microspheres in the tissue samples were: cerebrum $32043 \pm 3784$, cerebral gray matter $1426 \pm 157$, cerebral white matter $392 \pm 53$, caudate nucleus $1167 \pm 152$, hippocampus $960 \pm 133$, thalamus-hypothalamus $4210 \pm 622$, midbrain $2581 \pm 329$, cerebellum $7487 \pm 1002$, pons $1395 \pm$ 335 , and medulla $2768 \pm 437$.

To assure that the ligation of both external jugular veins did not increase the cerebral venous pressure and influence cerebral blood flow, four additional newborn piglets were studied before and after both external jugular veins were ligated. A longitudinal scalp incision was made over the sagittal suture, allowing scalp retraction and exposure of the calvarium. A 24-gauge Teflon catheter was inserted through the sagittal suture and dura into the superior sagittal sinus and glued into place. The sagittal venous pressure and brain blood flow were measured before and $1 \mathrm{~h}$ after both external jugular vein ligations.

Induction of hypoxia. The animals were allowed a 60 -min stabilization period after completion of surgery. After this, the animals were connected to a breathing circuit with a constant bias-flow of 3-4 L/min. After a 10 -min period of stable breathing in room air, lung function $\left(\dot{\mathrm{V}}_{\mathrm{E}}, \mathrm{V}_{\mathrm{t}}, \mathrm{Cdyn}\right.$, and $\left.\mathrm{R}_{\mathrm{L}}\right)$, cardiovascular measurements (ABP and CO), regional brain blood flow and arterial blood gas measurements were obtained and referred to as room air baseline. To induce hypoxia, the $\mathrm{FIO}_{2}$ was decreased to 0.10 within $6 \mathrm{~s}$ and the $\mathrm{O}_{2}$ concentration was monitored continuously by an oxygen analyzer (OM-15 Beckman Instruments, Anaheim, CA). After 1 and $5 \mathrm{~min}$ on $\mathrm{FIO}_{2}$ of 0.10 , cardiovascular measurements were performed and at $10 \mathrm{~min}$ of hypoxia all measurements were repeated including cerebral blood flow. All the measurements were taken only when the animals were resting quietly and without signs of distress as evidenced by stable heart rate and ABP recordings.

Data analysis. Changes in cardiovascular and respiratory measurements between RA and during hypoxia were compared by the paired $t$ test. Bonferroni correction was used for multiple comparisons.

Repeated measures analysis of variance followed by Duncan's multiple range test was used to compare the pattern of response to hypoxia between the $\uparrow \dot{V}_{\mathrm{E}}$ and $\downarrow \dot{V}_{\mathrm{E}}$ groups at 1,5 , and $10 \mathrm{~min}$ of hypoxia for $\dot{\mathrm{V}}_{E}, \mathrm{ABP}$, and $\mathrm{CO}$. A one-way analysis of variance was used to compare the arterial blood gas values and respiratory variables between the two groups of animals.

\section{RESULTS}

The ventilatory response to hypoxia differed among the animals and for this reason the results were analyzed separately in two groups. Although all animals increased $\dot{V}_{E}$ during the 1st min of hypoxia, only nine animals (mean $\pm \mathrm{SD}$; age $5 \pm 1.3 \mathrm{~d}$; wt $1.828 \pm 0.437 \mathrm{~kg}$ ) sustained the increase in ventilation at 10 min of hypoxia ( $\uparrow \dot{V}_{E}$ group). The remaining eight animals (age, $5 \pm 1.2 \mathrm{~d} ; w t, 1.751 \pm 0.168 \mathrm{~kg}$ ) had a lower $\dot{\mathrm{V}}_{\mathrm{E}}$ at $10 \mathrm{~min}$ of hypoxia when compared to their RA baseline ( $\downarrow \dot{\mathrm{V}}_{\mathrm{E}}$ group) (Fig 1).

The respiratory rate did not change significantly with hypoxia in the $\uparrow \dot{V}_{E}$ animals, but in the $\downarrow \dot{V}_{E}$ group the rate was lower than baseline after $10 \mathrm{~min}$ of hypoxia. $V_{t}$ increased significantly with hypoxia only in the $\uparrow \dot{V}_{E}$ group. Although $\dot{V}_{E}$ with hypoxia remained $28.1 \pm 3.4 \%$ above baseline in the $\uparrow \dot{V}_{E}$ group, in the $\downarrow \dot{V}_{E}$ group it decreased to values significantly lower than baseline at $10 \mathrm{~min}$ of hypoxia (Table 1).

The decrease in $\mathrm{PaO}_{2}$ while breathing $10 \%$ oxygen was similar in both groups but $\mathrm{PaCO}_{2}$ decreased only in the group of animals

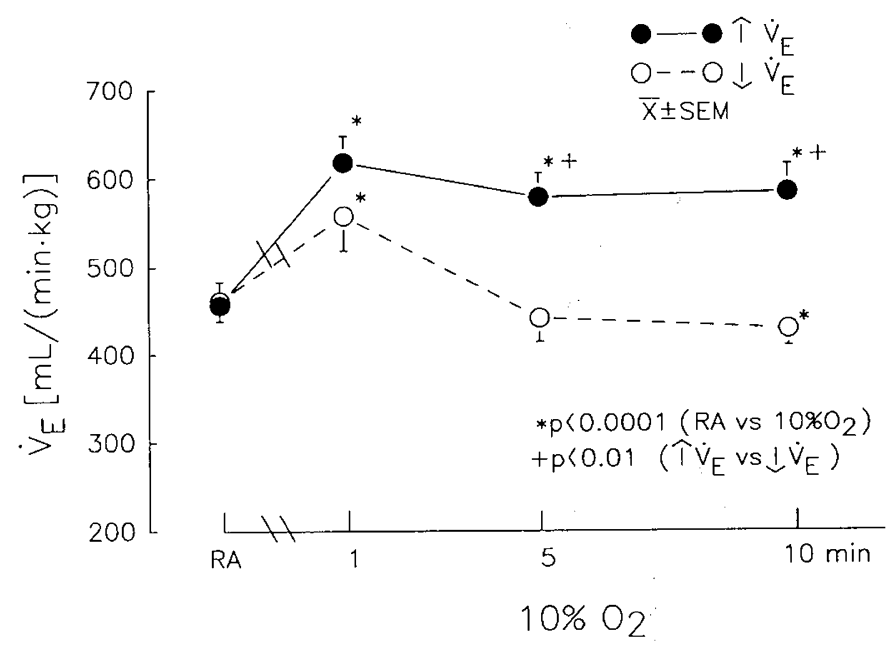

Fig. 1. Changes in $\dot{V}_{E}$ between normoxia and after 10 min of hypoxia in the $\uparrow \dot{\mathrm{V}}_{\mathrm{E}}$ and $\downarrow \dot{\mathrm{V}}_{\mathrm{E}}$ groups. 
Table 1. Arterial blood gases, ventilation, BBF and BSBF values obtained during normoxia and after 10 min of hypoxia in the group of animals that sustained $\left(\uparrow \dot{V}_{\mathrm{E}}\right)$ and did not sustain $\left(\downarrow \dot{V}_{\mathrm{E}}\right)$ increased minute ventilation during hypoxia (mean \pm SEM)

\begin{tabular}{|c|c|c|c|c|}
\hline & \multicolumn{2}{|c|}{$\uparrow \dot{\mathrm{V}}_{\mathrm{E}}(n=9)$} & \multicolumn{2}{|c|}{$\downarrow \dot{V}_{\mathrm{E}}(n=8)$} \\
\hline & Room air & $10 \% \mathrm{O}_{2}$ & Room air & $10 \% \mathrm{O}_{2}$ \\
\hline $\mathrm{pH}(\mathrm{U})$ & $7.39 \pm 0.01$ & $7.40 \pm 0.01$ & $7.40 \pm 0.02$ & $7.38 \pm 0.01$ \\
\hline $\mathrm{PaO}_{2}(\mathrm{kPa})$ & $11.5 \pm 0.4$ & $3.9 \pm 0.1^{*}$ & $11.5 \pm 0.5$ & $3.6 \pm 0.1^{*}$ \\
\hline $\mathrm{PaCO}_{2}(\mathrm{kPa})$ & $5.3 \pm 0.3$ & $4.6 \pm 0.2^{*}$ & $5.6 \pm 0.2$ & $5.5 \pm 0.2 \uparrow$ \\
\hline$\left[\mathrm{HCO}^{-}\right](\mathrm{mmol} / \mathrm{L})$ & $23.2 \pm 1.1$ & $21.4 \pm 1.1^{*}$ & $26.4 \pm 1.5$ & $24.6 \pm 1.3^{*}$ \\
\hline RR (breaths/min) & $76 \pm 7$ & $85 \pm 4$ & $85 \pm 6$ & $72 \pm 7^{*}$ \\
\hline $\mathrm{V}_{\mathrm{t}}(\mathrm{mL} / \mathrm{kg})$ & $6.2 \pm 0.5$ & $7.0 \pm 0.5 \ddagger$ & $5.6 \pm 0.4$ & $6.2 \pm 0.5$ \\
\hline$\dot{V}_{\mathrm{E}}[\mathrm{mL} /(\mathrm{min} \cdot \mathrm{kg})]$ & $456 \pm 27$ & $582 \pm 32 *$ & $461 \pm 22$ & $427 \pm 19^{*} \dagger$ \\
\hline $\mathrm{BBF}[\mathrm{mL} /(\mathrm{min} \cdot 100 \mathrm{~g})]$ & $83 \pm 9$ & $157 \pm 16^{*}$ & $72 \pm 11$ & $141 \pm 12^{*}$ \\
\hline $\mathrm{BSBF}[\mathrm{mL} /(\mathrm{min} \cdot 100 \mathrm{~g})]$ & $104 \pm 14$ & $213 \pm 17^{*}$ & $95 \pm 18$ & $188 \pm 20^{*}$ \\
\hline
\end{tabular}

$* p<0.001$ (RA versus $\left.10 \% \mathrm{O}_{2}\right)$.

$\dagger p<0.05\left(\uparrow \dot{\mathrm{V}}_{\mathrm{E}}\right.$ versus $\downarrow \dot{\mathrm{V}}_{\mathrm{E}}$ groups $) .1 \mathrm{~mm} \mathrm{Hg}=0.1333 \mathrm{kPa}$.

$\ddagger p<0.04$ (RA versus $10 \% \mathrm{O}_{2}$ ).

that continued to hyperventilate after $10 \mathrm{~min}$ of hypoxia $\left(\uparrow \dot{\mathrm{V}}_{\mathrm{E}}\right.$ group), whereas in $\downarrow \mathrm{V}_{\mathrm{E}}$ animals the $\mathrm{PaCO}_{2}$ remained unchanged (Table 1).

The changes in $\mathrm{CO}$ and $\mathrm{ABP}$ in the two groups are shown in Figure 2. $\mathrm{CO}$ was higher in the $\uparrow \dot{V}_{\mathrm{E}}$ group while breathing $\mathrm{RA}$ and this difference persisted during hypoxia; however, the percentage increase in $\mathrm{CO}$ during hypoxia was not different between groups. Conversely, ABP was similar in both groups under basa conditions but increased significantly at 1 and 5 min of hypoxia only in those animals who showed a sustained elevation in ventilation with hypoxia $(p<0.01)$.

The changes in BBF and BSBF with hypoxia are shown in Table 1. Basal values were similar in the two groups of animals.
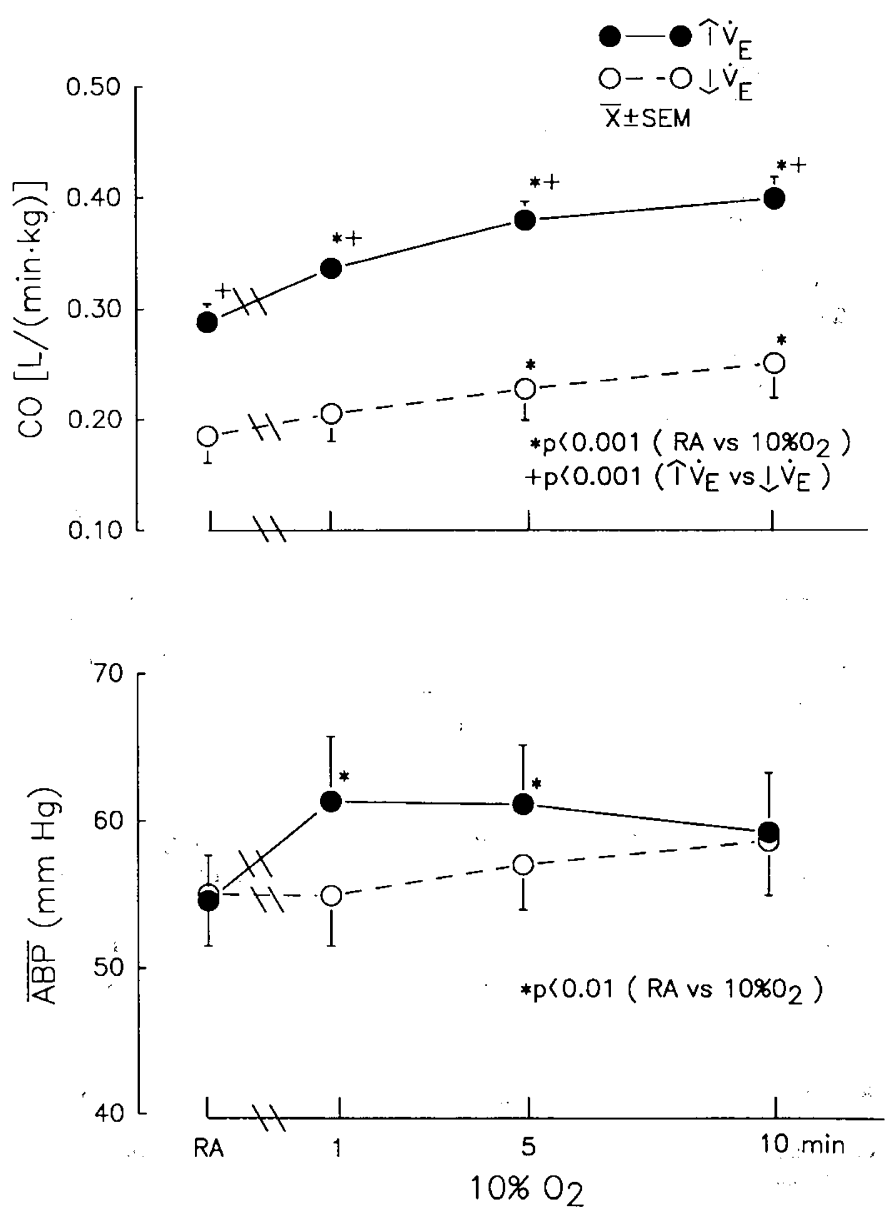

Fig. 2. Changes in $\mathrm{CO}$ and mean $\mathrm{ABP}$ during hypoxia in the $\uparrow \dot{\mathrm{V}}_{\mathrm{E}}$ and $\downarrow \dot{V}_{\mathrm{E}}$ groups.
During hypoxia, total $\mathrm{BBF}$ increased by more than $50 \%$ and BSBF nearly doubled in both groups $(p<0.0001)$. No correlation was found between the changes in ventilation and BBF or BSBF with hypoxia when the results were analyzed as absolute values or as a percent change from basal values (Fig. 3).

There were no differences in the sagittal venous pressure $[10$ \pm 1 to $10 \pm 0.3 \mathrm{~mm} \mathrm{Hg}$ ) and brain blood flow $(97 \pm 13$ to $93 \pm$ $14 \mathrm{~mL} /(\mathrm{min} \cdot 100 \mathrm{~g})]$ in the animals before and after both external jugular veins were ligated.
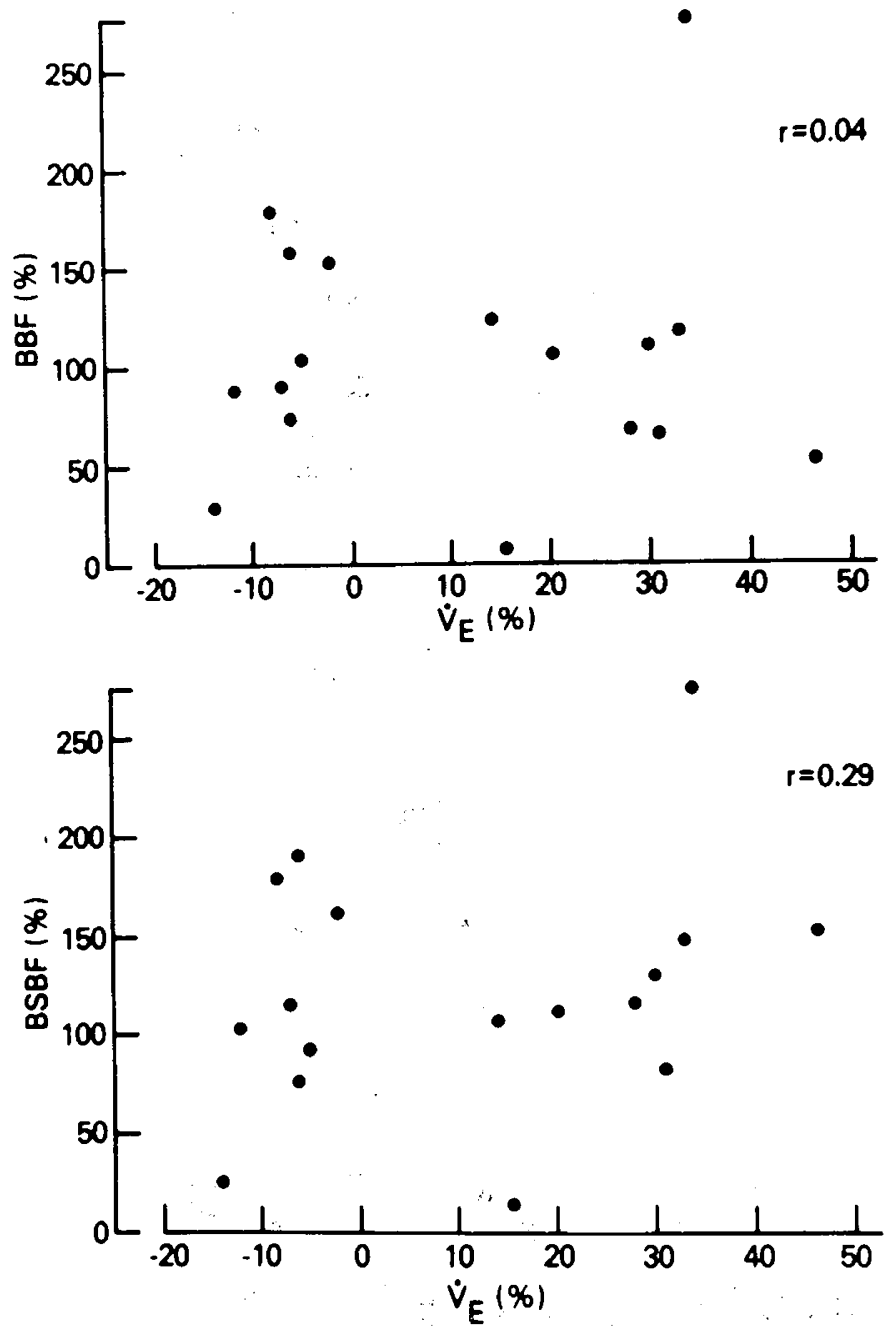

Fig. 3. Changes in BBF and BSBF and $\dot{V}_{E}$ after 10 min of hypoxia expressed as a percent of change. 
Cdyn and $\mathrm{R}_{\mathrm{L}}$ were not different between the groups under basal conditions or after $10 \mathrm{~min}$ of hypoxia.

\section{DISCUSSION}

We have taken advantage of the fact that our studies in the neonatal piglet have revealed that some animals have a ventilatory response to hypoxia similar to the adult response with sustained hyperventilation during hypoxia whereas other animals of a similar age have a neonatal type of response and do not maintain hyperventilation during hypoxia. This provided us with the opportunity to compare the ventilatory and hemodynamic response to hypoxia in these two groups of animals.

Numerous studies have attempted to elucidate the mechanisms responsible for the ventilatory depression that is seen after a few minutes of hypoxia in the neonate $(2-5,7-14)$. Some investigators have suggested that the ventilatory depression during sustained hypoxia could be due to a relative alkalosis of the brain stem structures produced by a washout of carbon dioxide that result from the increase in brain blood flow that occurs during hypoxia $(15,20)$. Neubauer et al. (15) produced an increase in cerebral perfusion pressure and blood flow by obstructing aortic flow with a balloon in adult chemodenervated cats. This maneuver resulted in a decrease in $\dot{V}_{\mathrm{E}}$ that was attributed to the increase in brain blood flow and rise in the ventral medullary surface $\mathrm{pH}$. However, this mechanism has been questioned by Javaheri and Teppema (21) who showed decrease in $\dot{V}_{E}$ during hypoxia without changes in ventral medullary extracellular $\mathrm{PCO}_{2}$ or $\mathrm{pH}$. Extending these findings, Brown and Lawson (22) demonstrated an acidotic shift in brain stem extracellular fluid during the late ventilatory depression in neonatal piglets. Also, Suzuki et al. (23) recently showed no differences in jugular venous $\mathrm{PCO}_{2}$ (which was used as an index of brain tissue $\mathrm{PCO}_{2}$ ) between human adults with sustained and unsustained ventilatory response to hypoxia.

Conversely, Edelman et al. (16) showed that adults with familial dysautonomia and goats treated with $\alpha$-adrenergic blockers have an absence of the normal cardiovascular response to hypoxia that is associated with a depression of the ventilatory response to hypoxia. They attributed the ventilatory depression to hypoxic central depression that was aggravated by a decreased cerebral blood flow due to arterial hypotension. Furthermore, neonatal kittens exposed to $6-12 \% \mathrm{O}_{2}$ display marked ventilatory depression, which in most instances is accompanied by a significant fall in ABP (1).

To our knowledge our data are the first to attempt to establish a relationship between changes in cerebral blood flow and the ventilatory response to hypoxia in newborn animals. Our data are not comparable to those reported by Neubauer et al. (15), because they induced an increase in brain blood flow by rapid inflation of an aortic balloon that allowed very short periods of observation and the results were based on only three breaths. Our study does not support the hypothesis that changes in brain stem perfusion during hypoxia influence the pattern of ventilatory response to low inspired oxygen. Although the ventral medullary extracellular $\mathrm{pH}$ was not measured in this study, the similar increase in the BBF and BSBF during hypoxia, irrespective of the pattern of the ventilatory response, suggests that possible brain stem alkalosis caused by the increase in brain blood flow is not a major factor for the late ventilatory depression in the newborn piglet.

It has been suggested that changes in pulmonary mechanics may also contribute to the hypoxic ventilatory depression in the newborn $(3,14)$. However, in our study no significant changes in lung compliance or total $R_{L}$ occurred in either group of animals studied, eliminating this as a possible explanation for the observed difference in ventilatory response.

A decrease in the metabolic rate during hypoxia has been described in different neonatal animal species and may also explain the decrease in ventilation after a few min of hypoxia (13). Oxygen consumption was not measured in our study but the fact that $\mathrm{PaCO}_{2}$ remained relatively constant during hypoxia in the animals that hypoventilated suggests that any reduction in metabolic rate during hypoxia was not enough to explain the absence of hyperventilation. In addition, recent studies in our laboratory did not demonstrate a clear relationship between changes in oxygen consumption and ventilation during hypoxia in newborn piglets (24).

The finding that the $\mathrm{CO}$ and $\mathrm{ABP}$ were lower in animals that did not sustain hyperventilation is interesting and raises the possibility that impaired perfusion to respiratory organs such as the respiratory muscles may contribute to the depressed ventilatory response in these animals. However, the magnitude of increase in $\mathrm{CO}$ during hypoxia was similar in both groups and ABP values at $10 \mathrm{~min}$ of hypoxia did not differ from baseline. We do not have an explanation for the large difference in $\mathrm{CO}$ between the two groups, because there were no differences in age, wt, hematocrit, or general condition of the animals that could explain this finding.

Although it is possible that sedation may influence the changes in ventilation during hypoxia, it is unlikely that the different hypoxic ventilatory response was related to the chloral hydrate administration because the dose of the drug was similar in both groups. Also, it has been shown that even at a higher dose $(250$ $\mathrm{mg} / \mathrm{kg}$ ) than the one used in this study, chloral hydrate does not affect the ventilatory response to hypoxia or hypercarbia in rabbits (25). In addition, a biphasic ventilatory response to hypoxia has been described in anesthetized and unanesthetized newborn animals $(1-4,7,10,14)$. Although it would have been preferable to perform our study in unanesthetized newborn piglets, it would be impossible to obtain all the necessary measurements during normoxia and hypoxia without causing significant distress to the animals.

We do not have a clear explanation for the two different patterns of ventilatory response to hypoxia. However, it has been reported that this response can vary widely among healthy subjects and newborn piglets $(4,22,26,27)$. It has also been suggested that genetic factors may play a significant role in determining this variability, based on studies on identical and nonidentical twins $(26,28)$. Vizek et al. (29) have suggested that the variability of the hypoxic ventilatory response may in part be associated with the differences in peripheral chemoreceptor sensitivity. In contrast, previous reports have demonstrated sustained increase of carotid sinus nerve activity during hypoxia even though there was a late decrease in ventilation $(1,30)$. However, this does not exclude the possibility that the decline in carotid body chemoreceptor activity during prolonged exposure to hypoxia may contribute to the biphasic respiratory pattern (11).

In conclusion, the results of this study do not support the hypothesis that the hypoxic ventilatory depression in neonatal piglets is related to changes in brain blood flow. Although the cardiovascular response to hypoxia was different in animals with different ventilatory responses, we were unable to establish a clear relationship between the circulatory and ventilatory response to hypoxia in these animals.

Acknowledgments. The authors thank Ralph N. Cicalese and Jean Fleurantin for their invaluable technical assistance, Cristina Varga for her secretarial support, Dr. Shahnaz Duara and Dr. Ronald N. Goldberg for their critical review of the manuscript, and Dr. Maria Delivoria-Papadopoulos and Dr. Craig Wagerle for helpful suggestions concerning microsphere methodology.

\section{REFERENCES}

1. Blanco CE, Hanson MA, Johnson P, Rigatto H 1984 Breathing pattern of kittens during hypoxia. J Appl Physiol 56:12-17

2. Grunstein MM, Hazinski TA, Schlueter MA 1981 Respiratory control during hypoxia in newborn rabbits: implied action of endorphins. J Appl Physiol 51:122-130

3. LaFramboise WA, Guthrie RD, Standaert TA, Woodrum DE 1983 Pulmonary mechanics during the ventilatory response to hypoxemia in the newborn monkey. J Appl Physiol 55:1008-1014 
4. Lawson EE, Long WA 1983 Central origin of biphasic breathing pattern during hypoxia in newborns. J Appl Physiol 55:483-488

5. Long WA, Lawson EE 1984 Neurotransmitters and biphasic respiratory response to hypoxia. J Appl Physiol 57:213-222

6. Rigatto H, Brady JP 1972 Periodic breathing and apnea in preterm infants. I. Evidence for hypoventilation possibly due to central respiratory depression. Pediatrics 50:202-218

7. Darnall Jr RA 1985 Aminophylline reduces hypoxic ventilatory depression: Possible role of adenosine. Pediatr Res 19:706-710

8. Guerra FA, Savich RD, Wallen LD, Lee CH, Clyman RI, Mauray FE Kitterman JA 1988 Prostaglandin $E_{2}$ causes hypoventilation and apnea in newborn lambs. J Appl Physiol 64:2160-2166

9. Hedner T, Hedner J, Bergman B, Iversen K, Jonason J 1983 Effects of GABA and some GABA analogues on respiratory regulation in the preterm rabbit. Biol Neonate 43:134-145

10. Long WA 1988 Prostaglandins and control of breathing in newborn piglets. $\mathrm{J}$ Appl Physiol 64:409-418

11. Carroll JL, Bureau MA 1987 Decline in peripheral chemoreceptor excitatory stimulation during acute hypoxia in the lamb. J Appl Physiol 63:795-802

12. LaFramboise WA, Woodrum DE 1985 Elevated diaphragm electromyogram during neonatal hypoxic ventilatory depression. J Appl Physiol 59:10401045

13. Mortola JP, Rezzonico R 1988 Metabolic and ventilatory rates in newborn kittens during acute hypoxia. Respir Physiol 73:55-68

14. Rigatto H, Wiebe C, Rigatto C, Lee DS, Cates D 1988 Ventilatory response to hypoxia in unanesthetized newborn kittens. J Appl Physiol 64:2544-2551

15. Neubauer JA, Santiago TV, Posner MA, Edelman NH 1985 Ventral medullary $\mathrm{pH}$ and ventilatory responses to hyperperfusion and hypoxia. J Appl Physiol 58:1659-1668

16. Edelman NH, Cherniack NS, Lahiri S, Richards E, Fishman AP 1970 The effects of abnormal sympathetic nervous function upon the ventilatory response to hypoxia. J Clin Invest 49:1153-1165

17. Mead J, Whittenberger JL 1953 Physical properties of human lungs measured during spontaneous respiration. J Appl Physiol 5:779-796
18. Heymann MA, Payne BD, Hoffman JIE, Rudolph AM 1977 Blood flow measurements with radionuclide-labeled particles. Prog Cardiovasc Dis 20:55-79

19. Wagerle LC, Kumar SP, Delivoria-Papadopoulos M 1986 Effect of sympathetic nerve stimulation on cerebral blood flow in newborn piglets. Pediatr Res 20:131-135

20. Nishimura M, Suzuki A, Nishiura Y, Yamamoto H, Miyamoto K, Kishi F Kawakami Y 1987 Effect of brain blood flow on hypoxic ventilatory response in humans. J Appl Physiol 63:1100-1106

21. Javaheri S, Teppema LJ 1987 Ventral medullary extra cellular fluid $\mathrm{pH}$ and $\mathrm{PCO}_{2}$ during hypoxemia. J Appl Physiol 63:1567-1571

22. Brown DL, Lawson EE 1988 Brain stem extracellular fluid pH and respiratory drive during hypoxia in newborn pigs. J Appl Physiol 64:1055-1059

23. Suzuki A, Nishimura M, Yamamoto H, Miyamoto K, Kishi F, Kawakami $Y$ 1989 No effect of brain blood flow on ventilatory depression during sustained hypoxia. J Appl Physiol 66:1674-1678

24. Suguihara C, Bancalari E, Hehre D, Duara S, Devia C, Gerhardt T 1989 Oxygen consumption and ventilatory response to hypoxia in the newborn piglet. Pediatr Res 25:328A(abstr)

25. Hunt CE, Hazinski TA, Gora P 1982 Experimental effects of chloral hydrate on ventilatory response to hypoxia and hypercarbia. Pediatr Res 16:79-91

26. Collins DD, Scoggin CH, Zwillich CW, Weil JV 1978 Hereditary aspects of decreased hypoxic response. J Clin Invest 62:105-110

27. Kawakami YH, Yamamoto T, Yoshikawa T, Shida A 1984 Chemical and behavioral control of breathing in adult twins. Am Rev Respir Dis 129:703707

28. Kawakami YT, Yoshikawa T, Shida A, Asanuma Y, Murao M 1982 Control of breathing in young twins. J Appl Physiol 52:537-543

29. Vizek M, Pickett CK, Weil JV 1987 Interindividual variation in hypoxic ventilatory response: potential role of carotid body. J Appl Physiol 63:18841889

30. Schweiler GH 1968 Respiratory regulation during postnatal development in cats and rabbits and some of its morphological substrate. Acta Physiol Scand [Suppl] 304:49-63 